\title{
The TIRI: A Rasch-Validated Revision of Resilience for Victims of Natural Disasters
}

\author{
Afdal Afdal ${ }^{1}$, Ifdil Ifdil ${ }^{2 *}$, Taufik Taufik ${ }^{3}$, Yuda Syahputra ${ }^{4}$, Lira Erwinda $^{5}$ \\ ${ }^{1234}$ Guidance and Counseling, Faculty of Education,Universitas Negeri Padang, Indonesia \\ ${ }^{5}$ Guidance and Counseling Department, Universitas Muhammadiyah Prof. Dr. HAMKA, South Jakarta, Indonesia
}

\begin{abstract}
This article presents the validation of Taufik \& Ifdil Resilienci Inventory (TIRI) in the context of post-natural disasters and in Indonesian. The quantitative research tests validity of TIRI with Rasch model analysis, TIRI is used to measure the resilience of students affected by natural disasters by the number items 43 and developed by the Indonesian Institute for Counseling, Education and Therapy (IICET) research team which is coordinated by the Research Center (Universitas Negeri Padang). This research was conducted 3 trials/cycle, all respondents per cycle were spread in 6 regencies in Kota in Indonesia. Instrument resilience for victims of natural disasters is valid and reliable (person reliability 0.68 and item reliability 0.99 ) with a total 25 items (Raw variance explained by measures $=23.5 \%$ with expected values of $24.3 \%$ ) valid from the total items of 43 items, that means items already represent measurements for the resilience of victims of natural disasters.
\end{abstract}

Keywords

Resilience; Post natural disasters; Validity; Reliability

Article Received: 20 September 2020, Revised: 30 November 2020, Accepted: 18 December 2020

\section{Introduction}

Resilience is defined as a dynamic process in which individuals display positive adaptations despite significant difficulties or trauma (Luthar \& Cicchetti, 2000). Whereas some other experts state that resilience has various meanings (Cutter, 2016; Goode, Salmon, Spencer, McArdle, \& Archer, 2017; Sharifi \& Yamagata, 2016). The diversity of meanings is a methodological challenge that is difficult to operational (Manyena, Machingura, \& O'Keefe, 2019). Apart from that a group of experts (Cutter, Ash, \& Emrich, 2014; Magis, 2010; Norris, Stevens, Pfefferbaum, Wyche, \& Pfefferbaum, 2008) believe that resilience is about the 'ability' or 'capacity' of a community to overcome disaster. So that capacity must be linked to the extent to which people live their daily lives before, during and after the stabilization event (Manyena, et al., 2019).

If resilience is associated with capacity, the higher the capacity in the individual, the higher the individual's ability to face a risk (Norris et al., 2008). The risk tends to be determined probabilistically as the impact of danger, exposure, vulnerability (Etinay, Egbu,
\& Murray, 2018). However, this does not mean that risks are objective hazards, threats or hazards that can be measured independently of social and cultural processes. In fact, risk is a product of historical, socio-political, and contingent viewpoints (Hardy \& Maguire, 2016; Manyena, Machingura, \& O'Keefe, 2019).

Regarding resilience, six quantitative instruments have emerged (Windle, Bennett, \& Noyes, 2011). Instruments can be given to assess resilience in adolescence regarding the strength of its development (Donnon \& Hammond, 2007) consisting of 94 items assessing 10 different protective factors, including The Resiliency Attitudes and Skill Profile (Hurtes \& Allen, 2001) to assess attitudes resilience; Measures of Resilience of Children and Adolescents (Ungar, 2008) to measure resilience of at-risk adolescents; Resilience Scale (Wagnild \& Young, 1993) to identify the degree of individual resilience; Resilience Scale for Adults (RSA;(Friborg, Hjemdal, Rosenvinge, \& Martinussen, 2003) measure personal and protective characteristics and coping forces that increase endurance; and Ego Resiliency (Bromley, 
Johnson, \& Cohen, 2006) to assess ego resiliency based on the trait of confident optimism, productive activity, insight and warmth, and skilled expression (Di Maggio, Ginevra, Nota, \& Soresi, 2016).

Furthermore, there is a resilience scale developed by Pesce et al. (Pesce et al., 2005) used to measure the level of positive psychosocial adaptation. It's just that this instrument was developed based on Brazilian Portuguese cross-culture and is considered less suitable for adoption in Indonesia because many items are not in accordance with cultural values. Based on these conditions, the right instrument is needed to measure the level of student resilience in the aftermath of the earthquake.

The urgency of developing resilience instruments is to determine the level of resilience of students in West Sumatra. The results of the instrument are used to prepare themselves to face the conditions of deterioration in the aftermath of the earthquake, if an earthquake occurs again is ready to face it and can also help others in the event of an earthquake. The development of resilience instruments can help researchers, counselors, psychologists to provide quick and appropriate interventions in increasing resilience in the aftermath of a catastrophic condition. The purpose of this research is to develop resilience instruments for victims of valid and reliable natural disasters and adjust them to religious values and culture in Indonesia.

\section{Method}

Quantitative research tests the validity of TIRI with Rasch modeling analysis. This research was conducted three times an experiment/cycle, namely: 1 st cycle $=308$ students $(\mathrm{M}=152$, and $\mathrm{F}=156), 2$ nd cycle $=$ 314 students $(\mathrm{M}=156$, and $\mathrm{F}=158)$, and the cycle $3 \mathrm{rd}=477$ students $(\mathrm{M}=237$, and $\mathrm{F}=$ 240), all respondents in each cycle aged 16 and 17 years, spread over six cities in the regency of West Sumatra. Students who are respondents were adolescents who experienced post-natural disasters and respondents who were sitting in high school were taken randomly. The instrument compiled by Taufik \& Ifdil (Taufik, 2015) was developed from theory (Reivich \& Shatté, 2002) with a total of 43 items for the initial stage before the cycle, and this instrument has seven aspects, that are: (1) Emotion Regulation, (2) Impulse Control, Optimism, (4) Causal Analysis, (5) Empathy, (6) Self-efficacy, and (7) Reaching Out. The data in this study are political data collected using the Taufik \& Ifdil Resilience Inventory (TIRI) instrument in the form of a Likert model scale with five alternative answers, including answer choices, namely: always, often, sometimes, rarely, and never. The Research data were analyzed using the Rasch model (Alagumalai, Curtis, \& Hungi, 2005; Bond, 2015; Sumintono \& Widhiarso, 2015) using statistical analysis of suitability using MNSQ outfit parameters with an ideal range $(+0.5$ to +1.5$)$, ZSTD outfit with a perfect range $(-2.0$ to +2.0$)$ to find the suitability of items and people, detect measurement biases, rating scales, strengths and weaknesses of items, and the level of difficulty of items from the ability of a person to answer and the ability of items to reveal the resilience of natural disaster victims (Sumintono \& Widhiarso, 2015).

\section{Result and Discussion}

This study discusses the development of the instrument through per cycle; that is, cycle 1 , cycle 2 , and cycle 3 , each cycle displays the reliability of items and person, separation index, measurement information, construct validity, item validity, the functioning of differential items, and rating validity.

\section{Reliability}

The reliability of an instrument refers to the stability of a measure and consistency in measurement. To get information about the reliability of the person and the reliability of 
items can be displayed in a statistical explained further in the following Table 1. summary. The statistical summary results are

Table 1. Summary statistics

\begin{tabular}{lllllll}
\hline Estimation & \multicolumn{2}{l}{ 1st cycle $=\mathbf{4 3}$ item } & \multicolumn{2}{l}{$\begin{array}{l}\text { 2nd cycle } \\
\text { item }\end{array}$} \\
\cline { 2 - 7 } & Person & Item & Person & Item & Person & Item \\
Reliability & .79 & .99 & .70 & .98 & .68 & .99 \\
Separation index & 1.95 & 10.57 & 1.52 & 7.61 & 1.47 & 9.29 \\
Mean Measure & .71 & .00 & .50 & .00 & .57 & .00 \\
Mean INFIT MNSQ & 1.03 & 1.04 & 1.02 & 1.01 & 1.02 & 1.01 \\
Mean OUTFIT MNSQ & 1.04 & 1.04 & 1.02 & 1.02 & 1.02 & 1.02 \\
Cronbach Alpha (KR-20) & $78 \%$ & & $66 \%$ & & $66 \%$ & \\
\hline
\end{tabular}

In Table 1 shows the results of three cycles, it can be seen the reliability score of the person in the first cycle is 0.79 , the second cycle $=$ 0.70 , and the third cycle $=0.68$, the results show each cycle has decreased reliability value, meaning the quality of the answers poor person provided and indicated misfit data or outliers. Along with the index separation also decreased in each cycle, meaning that the respondents' data distribution was not evenly distributed, possibly because the respondents were in the same condition (anxious, afraid, and sad) in working on the instrument. The results were obtained through the strata formula, $\mathrm{H}=[(4 *$ separation $)+1] / 3$ (Sumintono \& Widhiarso, 2015).

However, the center of attention is the item reliability score in each cycle remains perfect for $0.98-0.99$, meaning that the quality of the item is very excellent to reveal the resilience of victims of natural disasters. Furthermore, the Cronbach alpha value (KR-20) in each cycle starting from the first to the third decreased, meaning that the interaction between person and item was not excellent, this was due to the psychological condition of the students after the earthquake affected the performance in responding. In addition, item grouping is also discussed: the item index separation value in the 1 st cycle is known to be $10.57(\mathrm{H}=14.4)$, the 2 nd cycle $=7.61(\mathrm{H}=$ $10.48)$, and the 3 rd cycle $=9.29(\mathrm{H}=12.72)$. From the results of the separation item values in each cycle shows the results of a very very excellent stratum, where instruments can be grouped into 10 to 14 groups or instruments can measure people with very high to very low starting capabilities can be measured with this instrument. So, the value of item reliability is related to the value of separation, the two values support each other for a very excellent instrument quality, because the value of item reliability shows the perfect value so that separation also raises good results to measure with any ability (Alizamar et al., 2018).

\section{Construct Validity}

The construct validity explains how well the measurements are in accordance with theoretical expectations (Sumintono, B., \& Widhiarso, 2015). The point is that there are various measurements in various theoretical contexts, all of which must show relationships with other concepts that can be predicted and interpreted in that context. The instrument compiled by Taufik \& Ifdil (Taufik, 2015) was developed from the theory (Reivich \& Shatté, 2002) based on 7 aspects of resilience, namely: (1) Emotion Regulation, (2) Impulse Control, (3) Optimism, (4) Causal Analysis, (5) Empathy, (6) Self-efficacy, and (7) Reaching Out, the instrument is evaluated whether it is able to measure what should be measured. Analysis of construct validity uses' Principal Component Analysis (PCA) of residuals, which measures the extent to which 
the diversity of the resilience instrument measures what should be measured. PCA analysis uses 2 parameters, first the value of total raw variance in observation (minimum $20 \%$ ) and second value of total raw unexplained variance (minimum 15\%;
Linacre, 2011; Sumintono \& Widhiarso, 2015). Further information is presented in

Table 2 below.

Table 2. Standardized residual variance

\begin{tabular}{|c|c|c|c|c|}
\hline \multicolumn{5}{|l|}{1 st cycle $=43$ item } \\
\hline & \multicolumn{3}{|c|}{ Empirical } & Modeled \\
\hline Total raw variance in observations & 62.8 & $100.0 \%$ & & $100.0 \%$ \\
\hline Raw variance explained by measures & 19.8 & $31.6 \%$ & & $33.0 \%$ \\
\hline Raw unexplained variance (total) & 43.0 & $64.4 \%$ & $100.0 \%$ & $67.0 \%$ \\
\hline Unexplned variance in 1st contrast & 4.1 & $6.6 \%$ & $9.6 \%$ & \\
\hline Unexplned variance in $2 n d$ contrast & 2.8 & $4.5 \%$ & $6.5 \%$ & \\
\hline Unexplned variance in 3 rd contrast & 2.2 & $3.5 \%$ & $5.1 \%$ & \\
\hline Unexplned variance in 4 th contrast & 1.9 & $3.0 \%$ & $4.3 \%$ & \\
\hline Unexplned variance in 5 th contrast & 1.7 & $2.8 \%$ & $4.0 \%$ & \\
\hline \multicolumn{5}{|l|}{ 2nd cycle $=29$ item } \\
\hline Total raw variance in observations & 37.7 & $100.0 \%$ & & $100.0 \%$ \\
\hline Raw variance explained by measures & 8.7 & $23.2 \%$ & & $23.7 \%$ \\
\hline Raw unexplained variance (total) & 29.0 & $76.8 \%$ & $100.0 \%$ & $76.3 \%$ \\
\hline Unexplned variance in 1st contrast & 2.6 & $6.9 \%$ & $8.9 \%$ & \\
\hline Unexplned variance in $2 \mathrm{nd}$ contrast & 2.3 & $6.1 \%$ & $7.9 \%$ & \\
\hline Unexplned variance in 3 rd contrast & 1.8 & $4.8 \%$ & $6.2 \%$ & \\
\hline Unexplned variance in 4 th contrast & 1.7 & $4.6 \%$ & $6.0 \%$ & \\
\hline Unexplned variance in 5 th contrast & 1.5 & $4.1 \%$ & $5.3 \%$ & \\
\hline \multicolumn{5}{|l|}{ 3rd cycle $=25$ item } \\
\hline Total raw variance in observations & 32.7 & $100.0 \%$ & & $100.0 \%$ \\
\hline Raw variance explained by measures & 7.7 & $23.5 \%$ & & $24.3 \%$ \\
\hline Raw unexplained variance (total) & 25.0 & $76.5 \%$ & $100.0 \%$ & $75.7 \%$ \\
\hline Unexplned variance in 1st contrast & 3.0 & $9.3 \%$ & $12.2 \%$ & \\
\hline Unexplned variance in $2 n d$ contrast & 1.8 & $5.6 \%$ & $7.3 \%$ & \\
\hline Unexplned variance in 3 rd contrast & 1.7 & $5.1 \%$ & $6.6 \%$ & \\
\hline Unexplned variance in 4 th contrast & 1.5 & $4.5 \%$ & $5.9 \%$ & \\
\hline Unexplned variance in 5 th contrast & 1.3 & $4.1 \%$ & $5.4 \%$ & \\
\hline
\end{tabular}

In Table 2 above, we can see that the total raw variance of the first cycle is $31.6 \%$, not much different from the expected value of $33.0 \%$, the second cycle $=23.2 \%$ with the expected value of $23.7 \%$, and the third cycle $=23.5 \%$ with the value expectation of $24.3 \%$. This shows that the construct of the instrument is very good, meaning the items already represented measurements for resilience of victims of natural disasters, as well as the $20 \%$ unidimensional minimum requirements have been met (Linacre, 2011). While all unexplained variance results (1 st to 5 th) are below 15\%, which shows a good level of item independence in the instrument in each cycle. Thus this condition states that the instrument unidimensionality requirements are met for 43 items in cycle 1, 29 items in cycle 2, and 25 items in cycle 3 , furthermore, it can be stated that 25 items used in the resilience instrument are valid.

Based on the results of the standardized residual variance that the instrument is very 
good and the items available on the instrument are representative of measure the resilience of victims of natural disasters. Every measurement always produces information about the measurement results, meaning that the measurement results here is not information about the individual being measured, but the focus of measurement.
Measurement information depends on the relationship between the test and the individual being measured (Sumintono \& Widhiarso, 2014, 2015). For more details conveyed through the picture of the function of measurement information in each cycle as follows.
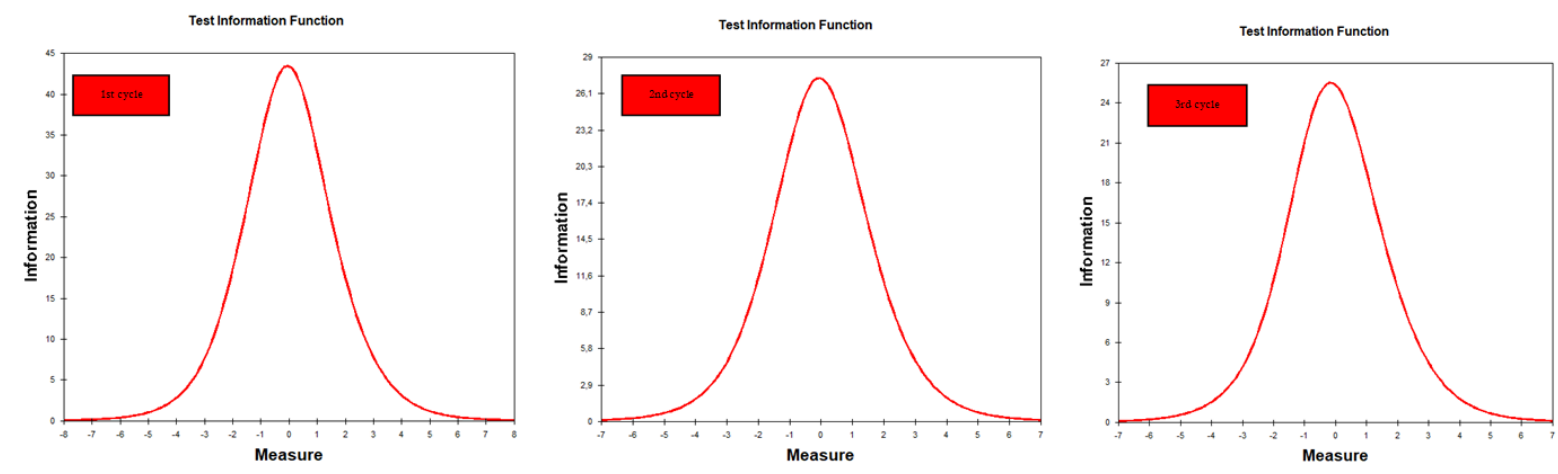

Figure 1. Measurement information function

From Figure 1, there are 3 boxes that describe each other's measurement information in each cycle, the first cycle can be seen as a measurement capable of measuring high groups of respondents, different from the second cycle and the third cycle that describes the measurements in both cycles began to form a larger curve than the one cycle curve. It means that it is increasingly helpful for normal and high curves, so the instrument is good because it can measure resilience capabilities from low to high (Sumintono \& Widhiarso, 2014). Vice versa, the smaller and lower the curve, the less able the instrument to measure high resilience capabilities (Sumintono \& Widhiarso, 2014). Next to clarify the measurement information in more detail through the item characteristic curves as follows.

In figure 2 each colored line is an ICC item in each cycle, colored lines (similar curves) in each cycle box are left-to-right according to the difficulty of the item. The red and pink curves on the left in the 1st cycle picture are items with codes Q32 and Q33, meaning the quality of the item is low or students find it difficult to never answer and the item passes through the $\mathrm{T}$ region ( 2 standard deviations) or the item is an outlier, whereas the green curve on the right (item Q4) indicates the quality of the item is high or students finds it difficult to give answers always and item Q4 includes items passed through outliers in the measurement of resilience of victims of natural disasters. After going through the 1st cycle, the items were re-evaluated from 43 to 29 items, meaning that the red curve on the left was eliminated in the development of the instrument.

In the second cycle with a total of 29 items, the light-blue curve on the right indicates an item Q43, meaning that the quality of both items is high, and the item passes through the $T$ region (two standard deviations) or the item is an outlier. In the evaluation phase of the 2 nd cycle, the items are aborted to maintain the quality of the measurement, the items after being evaluated become 29 , meaning that the light-blue curve on the right in the 2 nd cycle is eliminated in the development of the instrument. 

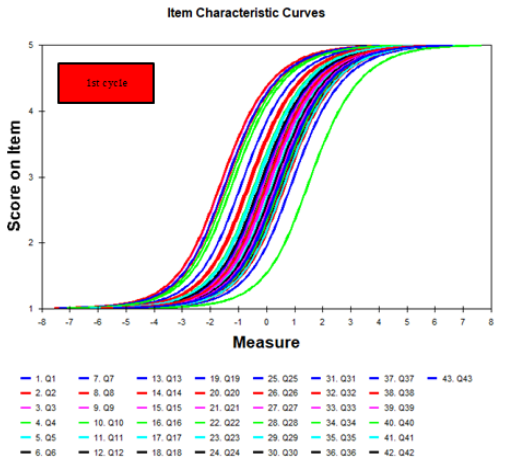

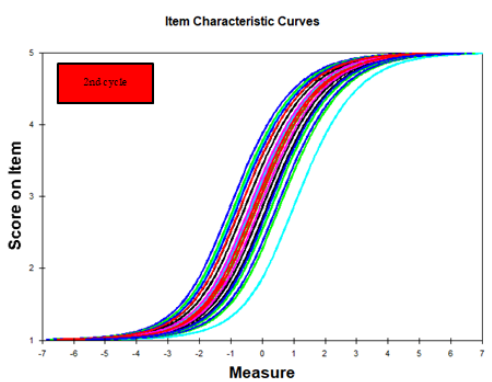

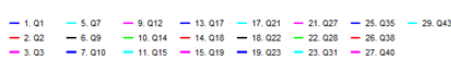

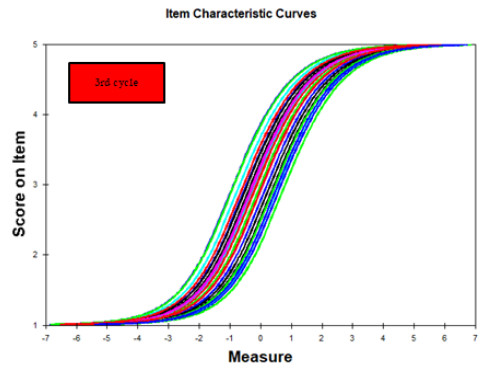

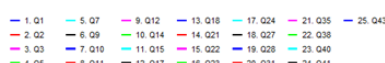

Figure 2. Item characteristic curve (ICC)

Furthermore, in the 3rd cycle with 25 colored curve items which indicates the items on the instrument are valid. To clarify and synchronize the evaluation of each cycle can be seen in the next analysis delivered via variable maps as follows.

\section{Instrument Validity}

Person and item validity using variable maps can show the distribution of students' abilities in the left and the level of difficulty items on the right (Sumintono \& Widhiarso, 2014). Further it is conveyed in Figure 3 below.

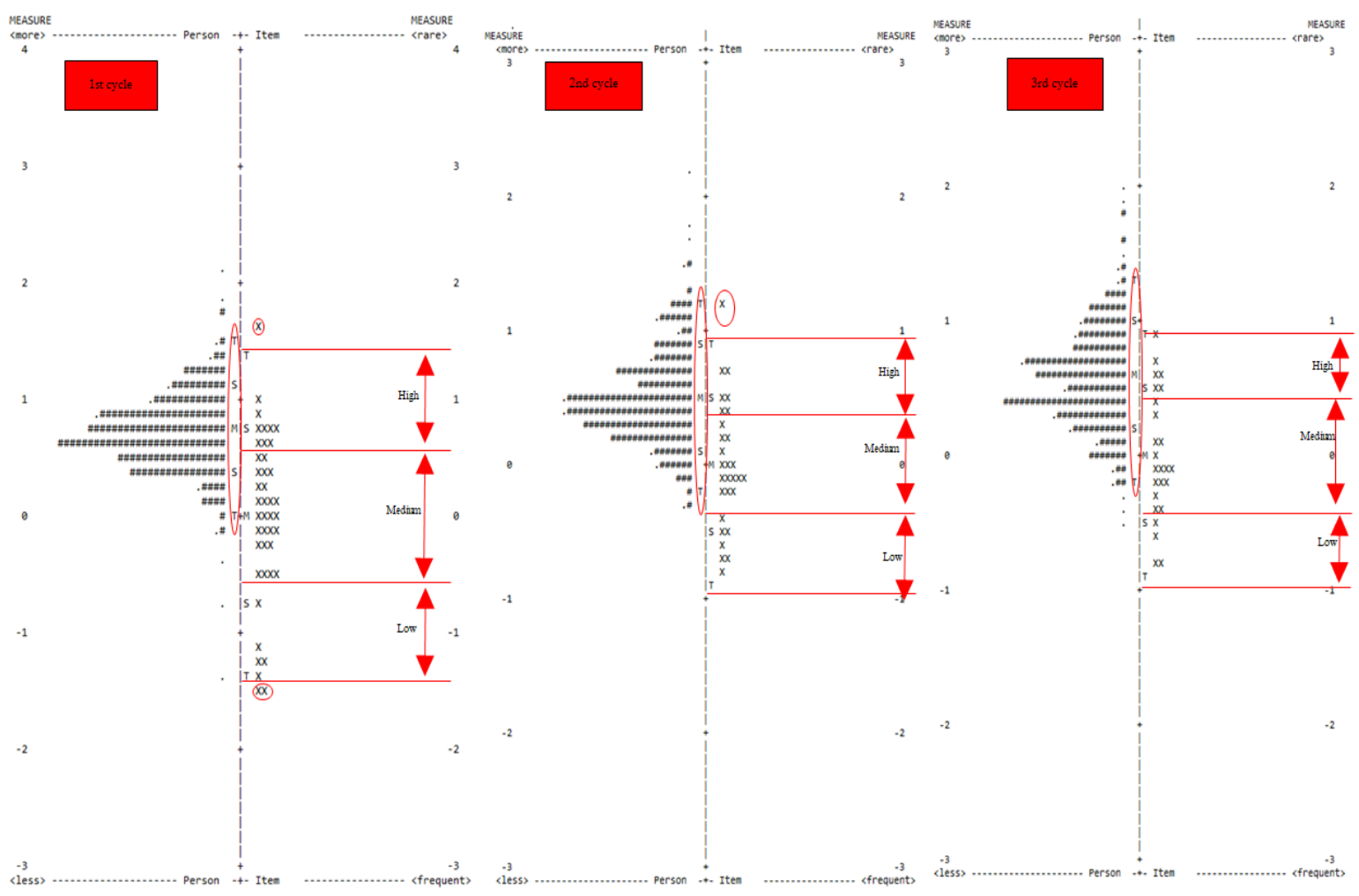

Figure 3.Variable maps 
In Figure 3 above shows the variable maps in each cycle, before being explained one by one of the variable maps for each cycle, it can be seen that the left Wright map is for viewing information from person and the right Wright map is for viewing the measurement functions of items. Before discussing the evaluation of each cycle, discussed together about the left map, the conditions seen in each cycle experienced a gathering of groups of respondents, meaning that respondents were not well distributed or with the catalyst of respondents in the same psychological condition so as to form groups as marked by a red circle on the logit measuring line. Other conditions that were the same for all respondents were the worst conditions, postdisaster misfortune (Habibah, Lestari, Oktaviana, \& Nashori, 2018), and extreme or misery (Tampi, Kumaat, \& Masi, 2013).

In cycle 1, three items (Q32, Q33, and Q4) were found that crossed the boundary of two standard deviations or outliers marked with a red circle. As explained earlier in Item Characteristic Curve that items Q32 and Q33 are the items that are most easily done by respondents or all respondents give answers 5 or 4 . In contrast to item $\mathrm{Q} 4$, items that are the most difficult to do are only a few respondents who are able to work on these items correctly. The evaluation results show that these three items are not well used to measure resilience for victims of natural disasters, so it needs to be aborted for the measurement conditions for victims of natural disasters.

In the second cycle, one Q43 item is found that exceeds the limit of two standard deviations or outliers marked with a red circle. As explained earlier in Item Characteristic Curve that item Q43 is the most difficult item for the respondent or all respondents give answers 1 or 2 . Evaluation results show that one item is not good enough to be used to measure resilience for victims of natural disasters, so it needs to be aborted for condition's measurement for victims of natural disasters.

In the third cycle with the number of items, 25 can be found good measurement conditions and in accordance with the logit line of resilience instruments for victims of natural disasters. However, it can be seen the distribution of items shows less evenly distributed from the logit from minus 3 to positive 3 . For that, additional items are very difficult and very easy to make good item distribution. Based on the results of this study supported by previous studies Erwinda, Syahputra, Fadli, \& Zola (Erwinda, Syahputra, Fadli, \& Zola, 2018) TIRI instruments are very good for conditions of measurement of resilience, both students with very high resilience and students with very low resilience can even be measured through the TIRI instrument. Furthermore, in this study also discussed the validity of each item, whether it is fit and appropriate for the measurement conditions as follows.

\section{Item validation}

Analyzing item measures can reveal statistical fit. The parameters used to show conformity are the outfits of the mean square with a middle square value of 1.0 or with an ideal range of $0.5>\mathrm{MNSQ}<1.5$ and Z-standardized values with a middle square value of 0.0 or with an ideal range of-2.0> ZSTD <+2.0 (Bond, 2015; Boone, Staver, \& Yale, 2013; Sumintono \& Widhiarso, 2015). More is conveyed in the following Table 3.

Table 3. Item misfit

\begin{tabular}{|c|c|c|c|c|c|c|c|c|}
\hline \multicolumn{3}{|l|}{ 1st cycle } & \multicolumn{3}{|l|}{ 2nd cycle } & \multicolumn{3}{|l|}{ 3rd cycle } \\
\hline \multirow{2}{*}{ \#Code Item } & \multicolumn{2}{|c|}{ OUTFIT } & \multirow{2}{*}{ \#Code Item } & \multicolumn{2}{|c|}{ OUTFIT } & \multirow{2}{*}{ \#Code Item } & \multicolumn{2}{|c|}{ OUTFIT } \\
\hline & MNSQ & ZSTD & & MNSQ & ZSTD & & MNSQ & ZSTD \\
\hline Q4 & 1.87 & 9.1 & Q12 & 1.39 & 4.6 & - & - & - \\
\hline Q6 & 1.72 & 8.8 & Q43 & 1.36 & 4.7 & & & \\
\hline Q37 & 1.45 & 5.9 & Q14 & 1.32 & 4.3 & & & \\
\hline
\end{tabular}


In Table 3, it shows the misfit order items in each cycle. In the first cycle there are three items, the second cycle also amounts to three items, and for the third cycle there are no misfit items. Judging from the MNSQ outfits ideal range (-1.5> MNSQ <+1.5) and standardized values (ZSTD) have already passed the ideal range $(-2.0>$ ZSTD <+2.0) so items need to be changed to fulfill the statement.

\section{Differential Items Functionality (DIF)}

Measurement instruments and items can be biased due to differences where certain items will favor one particular type (eg gender, religion, occupation, education, family background, etc.). The following Table 4 shows the results of the DIF analysis, which can be seen with the probability value below (0.05) showing items that are biased (Sumintono \& Widhiarso, 2015).
In table 4 above, it can be seen in cycle one there are 12 items are biased, the statements contained in the 12 items are more favorable to one respondent, so students are reluctant to give answers (for example: questions that are more favorable to women, so men ashamed to give an answer). Meanwhile, in cycle two there is one item that is biased and cycle three there is no bias (all statements are biased). The number of items that are biased shows that differences in student assessment of resilience for victims of natural disasters are influenced by various things, namely gender (Ifdil et al., 2018), parental educational backgrounds, culture (LaFromboise, Hoyt, Oliver, \& Whitbeck, 2006), economic level of parents, age, languages, natives and migrants had a significant relationship with resilience (Barends, 2004; Bonanno, Galea, Bucciarelli, \& Vlahov, 2007). In developing an instrument, it must pay attention to demographic characteristics, to minimize statements that contain bias (Linacre, 2011).

Table 4. Differential items functionality (DIF)

\begin{tabular}{llllll}
\hline 1st cycle & & 2nd cycle & & 3rd cycle & \\
\#Code Item & PROB. & \#Code Item & PROB. & \#Code Item & PROB. \\
\hline Q4 & .00 & Q31 & .03 & - & \\
Q6 & .03 & & & \\
Q8 & .00 & & & \\
Q13 & .00 & & & \\
Q25 & .01 & & & \\
Q26 & .00 & & & \\
Q29 & .01 & & & \\
Q30 & .00 & & & \\
Q36 & .04 & & & \\
Q37 & .02 & & & \\
Q39 & .00 & & & \\
Q42 & .01 & & & \\
\hline
\end{tabular}

Macedo, Kuspinar, Roberts, \& Maher (Macedo, Kuspinar, Roduta Roberts, \& Maher, 2019) health researchers revealed that the basic characteristics of each trial participant were collected at the first meeting before the first treatment began, checking including demographic characteristics such as age, sex (Ifdil, et al., 2018), duration pain and use of analgesic drugs with the response points provided yes or no.

\section{Rating Scale Validation}

A good instrument to use is an instrument that does not confuse respondents in choosing answers provided by the instrument itself. The rating scale given must be well understood by the respondent. 
The instrument uses a 5 point Likert scale presented in Figure 4 below. In figure 4 above shows the number $1=$ always, $2=$ often, $3=$ rarely, $4=$ sometimes, and $5=$ never. This means that the response point given by the resilience instrument has been understood by the respondent marked by the appearance of hills on the curve.
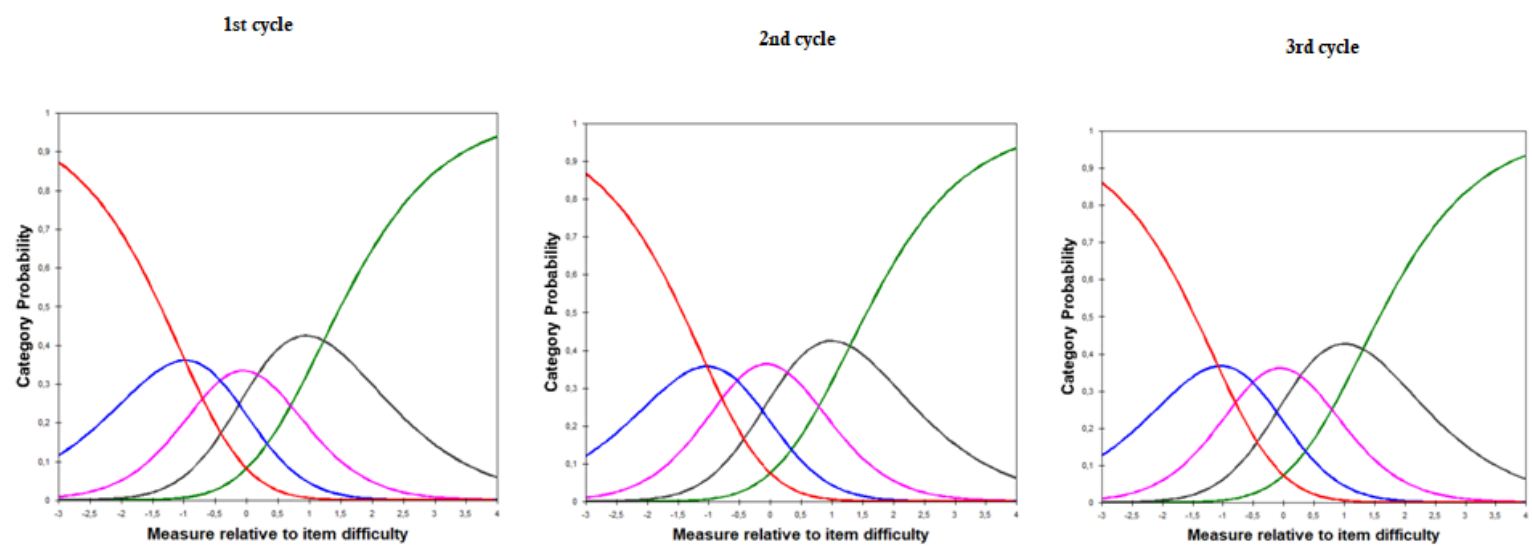

Figure 4. Probability of Response

The findings show that the five choices given were valid in resilience instruments for victims of natural disasters. From the above findings, it can be stated that the four response points are easily understood by the Indonesian people, meaning that the respondent is not confused by the choice of answers provided by the instrument and creates good results. The findings are supported by previous research (Alizamar, 2019) response point 4 is easily understood by the Indonesian people related to the validation of the FoMO internet ratting scale. Using resilience instruments for victims of natural disasters can measure emotion regulation, impulse control, optimism, causal analysis, empathy, self-efficacy, and reaching out (Reivich \& Shatté, 2002).

There is also a description of the resilience and experience of a person to a disaster that really determines what actions will be taken based on prior knowledge or experience, thereby increasing individual preparedness in dealing with disaster conditions if they occur again (Gowan, Kirk, \& Sloan, 2014). Therefore, preparing disaster preparedness early on for vulnerable communities is very important to avoid or minimize the risk of becoming a victim (Sutton \& Tierney, 2006). For this reason, it is necessary to have a measuring tool to measure post-disaster resilience, so that people can intervene in the psychological condition of individuals who experience natural disasters.

Mingxin, L., Zhanbiao, Zhen, Kan, \& Jianhua (Liu et al., 2011) revealed that the 2008 Sichuan earthquake in China destroyed cities and villages, and caused thousands of deaths. Based on these events the researchers found the reason children and adolescents in China could rise again after the sad events due to high resilience. Existing resilience capacity in the community is also needed to rebuild cities/villages from post-disaster devastation (Moreno, 2018). Based on the results of the study revealed that each cycle in the development of the instrument showed good results, especially for items that were statistically fit for the measurement conditions.

\section{Conclusions}

The findings show that the resilience instrument for victims of natural disasters is valid and reliable (person reliability is 0.68 and item reliability is 0.99 ) with a total of 25 valid items from a total of 43 instruments. This means that there are 18 items that do not fit the item validation standard. The development of this instrument was evaluated three times and re-analyzed by designing or revising statements that were not fit. The strength of resilience instruments for victims of natural disasters is to measure individual resilience in the aftermath of a disaster from high respondent groups to low groups. This instrument has seven aspects: emotion regulation, impulse control, 
optimism, causal analysis, empathy, self-efficacy, and reaching out (Reivich \& Shatté, 2002). This instrument is an alternative that can be used by counselors, psychologists, and researchers to uncover the resilience of individuals after natural disasters. Thus, the existence of this instrument can intervene in individuals who do not have the resilience of natural disasters to be provided responsive services, specifically in the function of understanding. For farther research, it can be combined with several other instrument variables for farther analysis of the differences or contingencies of these other variables.

\section{References}

[1] Alagumalai, S., Curtis, D. D., \& Hungi, N. (2005). Applied Rasch measurement: A book of exemplars: Springer.

[2] Alizamar, A. (2019). Application of Rasch Rating Scale Model to Analyze the Fear of Missing Out a Smartphone. ournal of Educational and Learning Studies, 2(1), 5055 .

[3] Alizamar, A., Ifdil, I., Taufik, T., Afdal, A., Hariko, R., Yendi, F. M., et al. (2018). Measuring internet addiction: adaptation and validation of the Chen Internet Addiction Scale (CIAS) on Indonesian version. Paper presented at the Journal of Physics: Conference Series.

[4] Barends, M. S. (2004). Overcoming adversity: An investigation of the role of resilience constructs in the relationship between socio-economic and demographic factors and academic coping. University of the Western Cape.

[5] Bonanno, G. A., Galea, S., Bucciarelli, A., \& Vlahov, D. (2007). What predicts psychological resilience after disaster? The role of demographics, resources, and life stress. Journal of consulting and clinical psychology, 75(5), 671.

[6] Bond, T. (2015). Applying the Rasch model: Fundamental measurement in the human sciences: Routledge.
[7] Boone, W. J., Staver, J. R., \& Yale, M. S. (2013). Rasch analysis in the human sciences: Springer.

[8] Bromley, E., Johnson, J. G., \& Cohen, P. (2006). Personality strengths in adolescence and decreased risk of developing mental health problems in early adulthood. Comprehensive psychiatry, 47(4), 315-324.

[9] Cutter, S. L. (2016). Resilience to what? Resilience for whom? The Geographical Journal, 182(2), 110-113.

[10] Cutter, S. L., Ash, K. D., \& Emrich, C. T. (2014). The geographies of community disaster resilience. Global environmental change, 29, 65-77.

[11] Di Maggio, I., Ginevra, M. C., Nota, L., \& Soresi, S. (2016). Development and validation of an instrument to assess future orientation and resilience in adolescence. Journal of adolescence, 51, 114-122.

[12] Donnon, T., \& Hammond, W. (2007). A psychometric assessment of the self-reported youth resiliency: Assessing developmental strengths questionnaire. Psychological reports, 100(3), 963-978.

[13] Erwinda, L., Syahputra, Y., Fadli, R. P., \& Zola, N. (2018). Rasch politomy analysis: measuring the level of student senior high school resilience after the disaster in West Sumatra. Konselor, 7(4), 138-144.

[14] Friborg, O., Hjemdal, O., Rosenvinge, J. H., \& Martinussen, M. (2003). A new rating scale for adult resilience: what are the central protective resources behind healthy adjustment? International journal of methods in psychiatric research, 12(2), 6576.

[15] Goode, N., Salmon, P. M., Spencer, C., McArdle, D., \& Archer, F. (2017). Defining disaster resilience: comparisons from key stakeholders involved in emergency management in Victoria, Australia. Disasters, 41(1), 171-193. 
[16] Gowan, M. E., Kirk, R. C., \& Sloan, J. A. (2014). Building resiliency: a cross-sectional study examining relationships among healthrelated quality of life, well-being, and disaster preparedness. Health and quality of life outcomes, 12(1), 85.

[17] Habibah, R., Lestari, S. D., Oktaviana, S. K., \& Nashori, F. (2018). Resiliensi pada Penyintas Banjir Ditinjau dari Tawakal dan Kecerdasan Emosi. Jurnal Psikologi Islam Dan Budaya, 1(1), 29-36.

[18] Hurtes, K. P., \& Allen, L. R. (2001). Measuring resiliency in youth: The resiliency attitudes and skills profile. Therapeutic recreation journal, 35(4), 333.

[19] Ifdil, I., Fadli, R. P., Syahputra, Y., Erwinda, L., Zola, N., \& Afdal, A. (2018). Rasch stacking analysis: differences in student resilience in terms of gender. Konselor, 7(3), 95-100.

[20] LaFromboise, T. D., Hoyt, D. R., Oliver, L., \& Whitbeck, L. B. (2006). Family, community, and school influences on resilience among American Indian adolescents in the upper Midwest. Journal of community psychology, 34(2), 193-209.

[21] Linacre, J. (2011). A user's guide to WINSTEPS [Computer Manual]. Chicago: Winsteps.

[22] Liu, M., Wang, L., Shi, Z., Zhang, Z., Zhang, K., \& Shen, J. (2011). Mental health problems among children one-year after Sichuan earthquake in China: a follow-up study. PloS one, 6(2), e14706.

[23] Luthar, S. S., \& Cicchetti, D. (2000). The construct of resilience: Implications for interventions and social policies. Development and psychopathology, 12(4), 857.

[24] Macedo, L. G., Kuspinar, A., Roduta Roberts, M., \& Maher, C. G. (2019). A Rasch analysis of the lumbar spine instability questionnaire. Physiotherapy Theory and Practice, 1-8.

[25] Magis, K. (2010). Community resilience: An indicator of social sustainability. Society and Natural Resources, 23(5), 401-416.

[26] Manyena, B., Machingura, F., \& O'Keefe, P. (2019). Disaster Resilience Integrated Framework for Transformation (DRIFT): A new approach to theorising and operationalising resilience. World Development, 123, 104587.

[27] Norris, F. H., Stevens, S. P., Pfefferbaum, B., Wyche, K. F., \& Pfefferbaum, R. L. (2008). Community resilience as a metaphor, theory, set of capacities, and strategy for disaster readiness. American journal of community psychology, 41(1-2), 127-150.

[28] Pesce, R. P., Assis, S. G., Avanci, J. Q., Santos, N. C., Malaquias, J. V., \& Carvalhaes, R. (2005). Cross-cultural adaptation, reliability and validity of the resilience scale. Cadernos de saude publica, 21(2), 436-448.

[29] Reivich, K., \& Shatté, A. (2002). The resilience factor: 7 essential skills for overcoming life's inevitable obstacles: Broadway books.

[30] Sharifi, A., \& Yamagata, Y. (2016). Urban resilience assessment: Multiple dimensions, criteria, and indicators Urban Resilience (pp. 259-276): Springer.

[31] Sumintono, B., \& Widhiarso, W. (2014). Aplikasi model Rasch untuk penelitian ilmuilmu sosial (edisi revisi): Trim Komunikata Publishing House.

[32] Sumintono, B., \& Widhiarso, W. (2015). Aplikasi pemodelan rasch pada assessment pendidikan: Trim komunikata.

[33] Sutton, J., \& Tierney, K. (2006). Disaster preparedness: Concepts, guidance, and research. Colorado: University of Colorado. 
[34] Tampi, B., Kumaat, L., \& Masi, G. (2013). Hubungan sikap dukungan sosial dengan tingkat resiliensi stres penyintas banjir di kelurahan Taas kecamatan Tikala kota Manado. Jurnal Keperawatan, 1(1).

[35] Taufik, T. (2015). Taufik \& Ifdil Resiliensi Inventori. Padang: Jurusan BK FIP UNP.

[36] Ungar, M. (2008). Resilience across cultures. The British Journal of Social Work, $38(2), 218-235$.

[37] Wagnild, G. M., \& Young, H. M. (1993). Development and psychometric. Journal of nursing measurement, 1(2), 165-17847.

[38] Windle, G., Bennett, K. M., \& Noyes, J. (2011). A methodological review of resilience measurement scales. Health and quality of life outcomes, 9(1), 8. 